\title{
JOSÉ LUIS S. LÓPEZ REYES
}

(1947-1992)

Nació en la ciudad de Tezcoco, el 29 de octubre de 1947. Ahí cursó la enseñanza primaria y secundaria. Lo conocí, en 1967, en San Ildefonso, nuestra querida Preparatoria Nocturna núm. 3. Desde entonces disfruté de su amistad.

En 1981 ingresó, como técnico académico, a la sección de investigación en archivos del Instituto de Investigaciones Estéticas de nuestra máxima casa de estudios. Su tarea más importante era la descripción de fuentes documentales para elaborar instrumentos de consulta que apoyaran las investigaciones sobre arte mexicano de los siglos XVI al XIX.

El primer fruto de su trabajo fue la segunda parte del Catálogo de documentos de arte del Ramo Matrimonios, del AGNM, que publicó la institución en 1985. A éste le siguió la Segunda Parte del Catálogo de documentos de arte del Ramo Templos y conventos, del mismo acervo, en cuatro tomos. Los tres primeros aparecieron en 1985, 86 y 88; el cuarto está en proceso de publicación.

En 1988 se tituló con la tesis: "La administración de bienes de los conventos femeninos de la ciudad de México", bajo la dirección del también desaparecido doctor José Guadalupe Victoria. Estudio que es un aporte a la historia de estas instituciones, y a la historia del arte colonial mexicano, pues, además de la información de primera mano que fundamenta las conclusiones del autor, pone de manifiesto la importancia de la acción administradora de los mayordomos de los conventos en relación con las obras arquitectónicas y ornamentales de los templos y las casa que poseían las órdenes de religiosas, y expresa que, al pretender rescatar la figura del mayordomo

... que estamos convencidos fue determinante en las relaciones de trabajo que se fincaron entre los artistas y las comunidades femeninas, así como en el proceso de creación de las obras de arte-desde la selección y compra de materiales, hasta la contratación de los ejecutantes-, creemos estar en posibilidad de aportar un nuevo enfoque dentro de la historiografía especializada; con la esperanza de poder ampliar en el futuro la visión sobre el arte novohispano que, bien a bien, aún resulta incompleta en muchos de sus aspectos (p. 118).

Después de titularse, José Luis prosiguió sus labores catalográficas y docentes. En 1991, redactó el artículo: "Doce textos sobre el arte virreinal" - -en el que comentó la sección "Viceregal art" del catálogo Mexico, Splendors of Thirty 
DOI: http://dx.doi.org/10.22201/iie.18703062e.1993.64.1663

Centuries-, que publicó la revista de la Escuela Nacional de Artes Plásticas (vol. 3, núms. 13/14, invierno 1991-1992).

Finalmente, el 24 de noviembre de 1992, falleció para alcanzar el descanso eterno.

Raguel Pineda Mendoza 